\title{
DC Education Reform Ten Years After, Part 2: Test Cheats
}

\author{
Richard P Phelps
}

Ten years ago, I worked as the Director of Assessments for the District of Columbia Public Schools (DCPS). For temporal context, I arrived after the first of the infamous test cheating scandals and left just before the incident that spawned a second. Indeed, I filled a new position created to both manage test security and design an expanded testing program. I departed shortly after Vincent Gray, who opposed an expanded testing program, defeated Adrian Fenty in the September 2010 DC mayoral primary. My tenure coincided with Michelle Rhee's last nine months as Chancellor.

The recurring test cheating scandals of the Rhee-Henderson years may seem extraordinary but, in fairness, DCPS was more likely than the average US school district to be caught because it received a much higher degree of scrutiny. Given how tests are typically administered in this country, the incidence of cheating is likely far greater than news accounts suggest, for several reasons:

- in most cases, those who administer tests - schoolteachers and administrators - have an interest in their results;

- test security protocols are numerous and complicated yet, nonetheless, the responsibility of non-expert ordinary school personnel, guaranteeing their inconsistent application across schools and over time;

- after-the-fact statistical analyses are not legal proof - the odds of a certain amount of wrong-to-right erasures in a single classroom on a paper-and-pencil test being coincidental may be a thousand to one, but one-in-a-thousand is still legally plausible; and 
- after-the-fact investigations based on interviews are time-consuming, scattershot, and uneven.

Still, there were measures that the Rhee-Henderson administrations could have adopted to substantially reduce the incidence of cheating, but they chose none that might have been effective. Rather, they dug in their heels, insisted that only a few schools had issues, which they thoroughly resolved, and repeatedly denied any systematic problem.

\section{Cheating scandals}

From 2007 to 2009 rumors percolated of an extraordinary level of wrong-toright erasures on the test answer sheets at many DCPS schools. "Erasure analysis" is one among several "red flag" indicators that testing contractors calculate to monitor cheating. The testing companies take no responsibility for investigating suspected test cheating, however; that is the customer's, the local or state education agency.

In her autobiographical account of her time as DCPS Chancellor, Michelle Johnson (nee Rhee), wrote (p. 197)

"For the first time in the history of DCPS, we brought in an outside expert to examine and audit our system. Caveon Test Security - the leading expert in the field at the time - assessed our tests, results, and security measures. Their investigators interviewed teachers, principals, and administrators.

"Caveon found no evidence of systematic cheating. None."

Caveon, however, had not looked for "systematic" cheating. All they did was interview a few people at several schools where the statistical anomalies were more extraordinary than at others. As none of those individuals would admit to knowingly cheating, Caveon branded all their excuses as "plausible" explanations. That's it; that is all that Caveon did. But, Caveon's statement that they found no evidence of "widespread" cheating - despite not having looked for it - would be frequently invoked by DCPS leaders over the next several years. ${ }^{1}$

1 A perusal of Caveon's website clarifies that their mission is to help their clients-state and local education departments-not get caught. Sometimes this means not cheating in the first place; other times it might mean 
Incidentally, prior to the revelation of its infamous decades-long, systematic test cheating, the Atlanta Public Schools had similarly retained Caveon Test Security and was, likewise, granted a clean bill of health. Only later did the Georgia state attorney general swoop in and reveal the truth.

In its defense, Caveon would note that several cheating prevention measures it had recommended to DCPS were never adopted. ${ }^{2}$ None of the cheating prevention measures that I recommended were adopted, either.

The single most effective means for reducing in-classroom cheating would have been to rotate teachers on test days so that no teacher administered a test to his or her own students. It would not have been that difficult to randomly assign teachers to different classrooms on test days.

The single most effective means for reducing school administrator cheating would have been to rotate test administrators on test days so that none managed the test materials for their own schools. The visiting test administrators would have been responsible for keeping test materials away from the school until test day, distributing sealed test booklets to the rotated teachers on test day, and for collecting re-sealed test booklets at the end of testing and immediately removing them from the school.

Instead of implementing these, or a number of other feasible and effective test security measures, DCPS leaders increased the number of test proctors, assigning each of a few dozen or so central office staff a school to monitor. Those proctors could not reasonably manage the volume of oversight required. A single DC test administration could encompass a hundred schools and a thousand classrooms.

\section{Investigations}

So, what effort, if any, did DCPS make to counter test cheating? They hired me, but then rejected all my suggestions for increasing security. Also, they

something else. One might argue that, ironically, Caveon could be helping its clients to cheat in more sophisticated ways and cover their tracks better.

2 Among them: test booklets should be sealed until the students open them and resealed by the students immediately after; and students should be assigned seats on test day and a seating chart submitted to test coordinators (necessary for verifying cluster patterns in student responses that would suggest answer copying). 
established a telephone tip line. Anyone who suspected cheating could report it, even anonymously, and, allegedly, their tip would be investigated.

Some forms of cheating are best investigated through interviews. Probably the most frequent forms of cheating at DCPS - teachers helping students during test administrations and school administrators looking at test forms prior to administration-leave no statistical residue. Eyewitness testimony is the only type of legal evidence available in such cases, but it is not just inconsistent, it may be socially destructive.

I remember two investigations best: one occurred in a relatively well-to-do neighborhood with well-educated parents active in school affairs; the other in one of the city's poorest neighborhoods. Superficially, the cases were similaran individual teacher was accused of helping his or her own students with answers during test administrations. Making a case against either elementary school teacher required sworn testimony from eyewitnesses, that is, studentseight-to-ten-year olds.

My investigations, then, consisted of calling children into the principal's office one-by-one to be questioned about their teacher's behavior. We couldn't hide the reason we were asking the questions. And, even though each student agreed not to tell others what had occurred in their visit to the principal's office, we knew we had only one shot at an uncorrupted jury pool.

Though the accusations against the two teachers were similar and the cases against them equally strong, the outcomes could not have been more different. In the high-poverty neighborhood, the students seemed suspicious and said little; none would implicate the teacher, whom they all seemed to like.

In the more prosperous neighborhood, students were more outgoing, freely divulging what they had witnessed. The students had discussed the alleged coaching with their parents who, in turn, urged them to tell investigators what they knew. During his turn in the principal's office, the accused teacher denied any wrongdoing. I wrote up each interview, then requested that each student read and sign.

Thankfully, that accused teacher made a deal and left the school system a few weeks later. Had he not, we would have required the presence in court of the eight-to-ten-year olds to testify under oath against their former teacher, who taught multi-grade classes. Had that prosecution not succeeded, the eyewitness 
students could have been routinely assigned to his classroom the following school year.

My conclusion? Only in certain schools is the successful prosecution of a cheating teacher through eyewitness testimony even possible. But, even where possible, it consumes inordinate amounts of time and, otherwise, comes at a high price, turning young innocents against authority figures they naturally trusted.

\section{Cheating blueprints}

Arguably the most widespread and persistent testing malfeasance in DCPS received little attention from the press. Moreover, it was directly propagated by District leaders, who published test blueprints on the web. Put simply, test "blueprints" are lists of the curricular standards (e.g., "student shall correctly add two-digit numbers") and the number of test items included in an upcoming test related to each standard. DC had been advance publishing its blueprints for years.

I argued that the way DC did it was unethical. The head of the Division of Data \& Accountability, Erin McGoldrick, however, defended the practice, claimed it was common, and cited its existence in the state of California as precedent. The next time she and I met for a conference call with one of DCPS's test providers, Discover Education, I asked their sales agent how many of their hundreds of other customers advance-published blueprints. His answer: none.

In the state of California, the location of McGoldrick's only prior professional experience, blueprints were, indeed, published in advance of test administrations. But their tests were longer than DC's and all standards were tested. Publication of California's blueprints served more to remind the populace what the standards were in advance of each test administration. Occasionally, a standard considered to be of unusual importance might be assigned a greater number of test items than the average, and the California blueprints signaled that emphasis.

In Washington, DC, the tests used in judging teacher performance were shorter, covering only some of each year's standards. So, DC's blueprints showed everyone well in advance of the test dates exactly which standards would be tested and which would not. For each teacher, this posed an ethical dilemma: should they "narrow the curriculum" by teaching only that content they knew would be tested? Or, should they do the right thing and teach all the standards, as they were legally and ethically bound to, even though it meant spending less time 
on the to-be-tested content? It's quite a conundrum when one risks punishment for behaving ethically.

Monthly meetings convened to discuss issues with the districtwide testing program, the DC Comprehensive Assessment System (DC-CAS) - administered to comply with the federal No Child Left Behind (NCLB) Act. All public schools, both DCPS and charters, administered those tests. At one of these regular meetings, two representatives from the Office of the State Superintendent of Education (OSSE) announced plans to repair the broken blueprint process. ${ }^{3}$

The State Office employees argued thoughtfully and reasonably that it was professionally unethical to advance publish DC test blueprints. Moreover, they had surveyed other US jurisdictions in an effort to find others that followed DC's practice and found none. I was the highest-ranking DCPS employee at the meeting and I expressed my support, congratulating them for doing the right thing. I assumed that their decision was final.

I mentioned the decision to McGoldrick, who expressed surprise and speculation that it might have not been made at the highest level in the organizational hierarchy. Wasting no time, she met with other DCPS senior managers and the proposed change was forthwith shelved. In that, and other ways, the DCPS tail wagged the OSSE dog.

$$
* * *
$$

It may be too easy to finger ethical deficits for the recalcitrant attitude toward test security of the Rhee-Henderson era ed reformers. The columnist Peter Greene insists that knowledge deficits among self-appointed education reformers also matter:

“... the reformistan bubble ... has been built from Day One without any actual educators inside it. Instead, the bubble is populated by rich people, people who want rich people's money, people who think they have great ideas about education, and even people who sincerely want to make education better. The bubble does not include people who can turn to an Arne Duncan or a Betsy DeVos or a Bill Gates and say, 'Based on my

3 Yes, for those new to the area, the District of Columbia has an Office of the "State" Superintendent of Education (OSSE). Its domain of relationships includes not just the regular public schools (i.e., DCPS), but also other public schools (i.e., charters) and private schools. Practically, it primarily serves as a conduit for funneling money from a menagerie of federal education-related grant and aid programs. 
years of experience in a classroom, I'd have to say that idea is ridiculous bullshit."”

"There are a tiny handful of people within the bubble who will occasionally act as bullshit detectors, but they are not enough. The ed reform movement has gathered power and money and set up a parallel education system even as it has managed to capture leadership roles within public education, but the ed reform movement still lacks what it has always lacked--actual teachers and experienced educators who know what the hell they're talking about."

In my twenties, I worked for several years in the research department of a state education agency. My primary political lesson from that experience, consistently reinforced subsequently, is that most education bureaucrats tell the public that the system they manage works just fine, no matter what the reality. They can get away with this because they control most of the evidence and can suppress it or spin it to their advantage.

In this proclivity, the DCPS central office leaders of the Rhee-Henderson era proved themselves to be no different than the traditional public-school educators they so casually demonized.

US school systems are structured to be opaque and, it seems, both educators and testing contractors like it that way. For their part, and contrary to their rhetoric, Rhee, Henderson, and McGoldrick passed on many opportunities to make their system more transparent and accountable.

Education policy will not improve until control of the evidence is ceded to genuinely independent third parties, hired neither by the public education establishment nor by the education reform club.

The author gratefully acknowledges the fact-checking assistance of Erich Martel and Mary Levy. 
Citation: Phelps, R. P. (2020, September). Looking Back on DC Education Reform 10 Years After, Part 2: Test Cheats. Nonpartisan Education Review / Testimonials. https://nonpartisaneducation.org/Review/Testimonials/v16n3.htm 